\title{
Ampullary Adenoma Treated by Endoscopic Double-Snare Retracting Papillectomy
}

Hiromitsu Soma*, Naoteru Miyata*, Shigenari Hozawa*, Hajime Higuchi*, Yoshiyuki Yamagishi*, Yuji Nakamura*, Keita Saeki*, Kaori Kameyama ${ }^{\dagger}$, Yohei Masugi ${ }^{\dagger}$, Naohisa Yahagi*, and Takanori Kanai*

Departments of *Internal Medicine and ${ }^{\dagger}$ Pathology, Keio University School of Medicine, Tokyo, Japan

We report herein improved methods for the safe and successful completion of endoscopic papillectomy (EP). Between January 2008 and November 2011, 12 patients underwent double-snare retracting papillectomy for the treatment of lesions of the major duodenal papilla. The main outcomes were en bloc resection rates, pathological findings, and adverse events. All of the patients (mean age, 60.1 years; range, 38 to 80 years) were diagnosed with ampullary adenoma by endoscopic forceps biopsies prior to endoscopic snare papillectomy. En bloc resection by double-snare retracting papillectomy was successfully performed for all lesions (median size, $12.3 \mathrm{~mm}$ ), comprising six tubular adenomas, one tubulovillous adenoma, three cases of epithelial atypia, one hamartomatous polyp, and one case of duodenitis with regenerative change. Significant hemorrhage and pancreatitis were observed in one case after EP. Adenoma recurrence occurred in three patients during follow-up (median, 28.5 months) at a mean interval of 2 months postoperatively (range, 1 to 3 months). No serious adverse events were observed. Double-snare retracting papillectomy is effective and feasible for treating lesions of the major duodenal papilla. Further treatment experience, including a single-arm phase II study, needs to be accumulated before conducting a randomized controlled study. (Gut Liver 2015;9:689-692)

Key Words: Argon plasma coagulation; Endoscopic papillectomy; Endosonography; Intraductal ultrasonography; Tubular adenoma

\section{INTRODUCTION}

Endoscopic papillectomy (EP) has evolved in recent years, and this technology has now been recognized as a safe and reliable treatment modality for benign tumors of the major duodenal papilla. $^{1-10}$ One of the advantages of this method is that it does not require general anesthesia. The proper indication for EP is commonly agreed to be nonmalignant adenoma of the papilla of Vater. EP can achieve complete en bloc resection of the lesion but may present technical difficulties in some cases. En bloc resection is fundamental for the treatment of neoplastic lesions and permits precise histopathologic evaluation of the specimen. ${ }^{5}$ Sometimes, tumors that are diagnosed as adenomas based on biopsy specimens may contain malignant cells within the entire resected tumor. Indeed, depending on the size of the adenoma and the presence of villous adenoma cells, carcinomatous cell deposits within the adenoma are found in 30\% of patients. ${ }^{11}$ We investigated endoscopic double-snare retracting papillectomy as a new approach to EP. This technology has been established by improving the conventional single-snare constriction method. The advantages of this method are (1) snare constriction can be performed safely and securely by observing the tumor margin under the endoscopic field; and (2) relatively deep vertical margins are obtained by pulling the tumor-grasping snare. Here, we report our experience with the use of this new EP technology.

\section{MATERIALS AND METHODS}

Between January 2008 and November 2011, 12 patients with tumors of the major duodenal papilla underwent EP. All of the patients provided informed consent for the procedure and were aware of the option for surgical treatment. The current retrospective study was approved by our Institutional Review Board. The patients included seven men and five women, with a median age of 60.1 years (range, 38 to 80 years). In all of the patients, a preprocedural diagnosis of adenoma was obtained by endoscopic biopsy. Tumor staging and ductal infiltration were estimated by endoscopic retrograde cholangiopancreatography (ERCP), endoscopic ultrasonography (EUS), or transpapillary in-

Correspondence to: Shigenari Hozawa

Department of Internal Medicine, Keio University School of Medicine, 35 Shinanomachi, Shinjuku-ku, Tokyo 160-8582, Japan

Tel: +81-3-3353-1211, ext. 62319, Fax: +81-3-3341-3631, E-mail: hozawas@a5.keio.jp

Received on June 2, 2014. Revised on September 4, 2014. Accepted on October 25, 2014. Published online June 19 , 2015

pISSN 1976-2283 eISSN 2005-1212 http://dx.doi.org/10.5009/gnl14206

@ This is an Open Access article distributed under the terms of the Creative Commons Attribution Non-Commercial License (http://creativecommons.org/licenses/by-nc/4.0) which permits unrestricted non-commercial use, distribution, and reproduction in any medium, provided the original work is properly cited. 
traductal ultrasonography (IDUS). None of the tumors infiltrated the bile duct or the pancreatic duct. Endoscopic double-snare retracting papillectomy was performed using a therapeutic duodenoscope with a 4.2-mm working channel (TJF-240; Olympus Optical, Tokyo, Japan). After viewing the precise extent of the tumor by spraying a $0.5 \%$ solution of indigo carmine onto the surface, high-frequency hexagonal snares (SD-6L-1, maximum loop diameter of $22 \mathrm{~mm}$; Olympus Optical) were inserted via the instrumental port. The "cutting snare" was hooked over the "pulling snare" before insertion. These two snares can be inserted into the same endoscope channel without tangling. The papillary tumor was grasped by the pulling snare and pulled toward the duodenal lumen, making it easier to completely snare the papillary lesion. After releasing the pulling snare, the base of the papillary tumor was looped, and the cutting snare was tightened at a safe margin. En bloc papillectomy was performed with a monopolar electrosurgical cutting current. A nasobiliary drainage tube was placed in the bile duct of all of the patients. A plastic stent tube was placed in the pancreatic duct of all of the patients to avoid post-ERCP pancreatitis. A follow-up endoscopy with biopsy was performed after 3, 6, and 12 months. In the case of benign recurrence, endoscopic retreatment was attempted in our department using the same techniques.

\section{RESULTS}

EP was technically feasible in all patients. The Table 1 shows the technical results of EP, including adverse events. The tumors had a median size of $12.4 \mathrm{~mm}$ (range, 8 to $20 \mathrm{~mm}$ ). En bloc excision was achieved in 12 cases (100\%). Biliary stents were placed in 12 patients (100\%), and pancreatic stents were placed in 11 patients (91.7\%). Hemorrhage was identified in one patient on the day after EP but was cured by endoscopic treatment. One patient had post-ERCP pancreatitis and recovered with medical treatment. No other short- or long-term adverse events were identified during follow-up (median, 28.5 months; range, 2 to 48 months). The final histopathological diagnosis was tubular adenoma in seven patients (58.3\%), tubulovillous adenoma in one (8.3\%), hamartomatous polyp in one (8.3\%), adenocarcinoma in adenoma in one (8.3\%), and no neoplastic lesion in two (16.6\%). Macro- and/or microscopic tumor recurrence was observed in three of the 12 patients (25.0\%) but was successfully eradicated by repeat EP and argon plasma coagulation in all three cases, as indicated in the Table 1.

\section{Case presentation}

A 63-year-old man was admitted to our department for the evaluation of an ampullary mass, detected by an endoscopy that was performed for screening purposes at a general hospital. He had no significant past medical or family history. The patient was asymptomatic, and no abnormal signs were evident upon physical examination. Laboratory data also showed no abnormalities. Computed tomography and magnetic resonance imaging revealed a 2-cm mass in the descending part of the duodenum. Duodenoscopy revealed a 2-cm-diameter exposed reddish mass in the papilla of Vater (Fig. 1A). Biopsy showed atypical cells. EUS and ERCP revealed a 20-mm hypoechoic mass in the papilla of Vater without invasion of the duodenum, pancreas, bile duct terminus, or main pancreatic duct terminus (Fig. 1B). The lesion was therefore considered eligible for EP. Endoscopic double-snare papillectomy was performed. By grasping and pulling the tumor with the pulling snare, the tumor was safely and easily grasped with the cutting snare (Fig. 1C). En bloc papillectomy was performed with a bipolar electrosurgical cutting current. A stent was placed in the

Table 1. Patient Characteristics and Technical Results

\begin{tabular}{|c|c|}
\hline Characteristic & Value \\
\hline No. of patients & 12 \\
\hline Gender, male/female & $7 / 5$ \\
\hline Age, yr & $60.1(38-80)$ \\
\hline Biliary cannulation & $12(100.0)$ \\
\hline Pancreatic cannulation & $11(91.7)$ \\
\hline Follow-up period, mo & $28.6(2-48)$ \\
\hline En bloc excision & $12(100.0)$ \\
\hline Recurrence rate & $3(25.0)$ \\
\hline Recurrence cases (size/pathological findings/period & Case 1 (14 mm/tubular adenoma with moderate to severe dysplasia/3 mo) \\
\hline \multirow[t]{2}{*}{ from EP to recurrence) } & Case 2 (10 mm/tubular adenoma/3 mo) \\
\hline & Case 3 (12 mm/atypical epithelium/4 mo) \\
\hline \multicolumn{2}{|l|}{ Adverse events } \\
\hline Short-term & Hemorrhage $(n=1)$, pancreatitis $(n=1)$ \\
\hline Long-term & None \\
\hline
\end{tabular}

Data are presented as number (\%) or mean (range). 

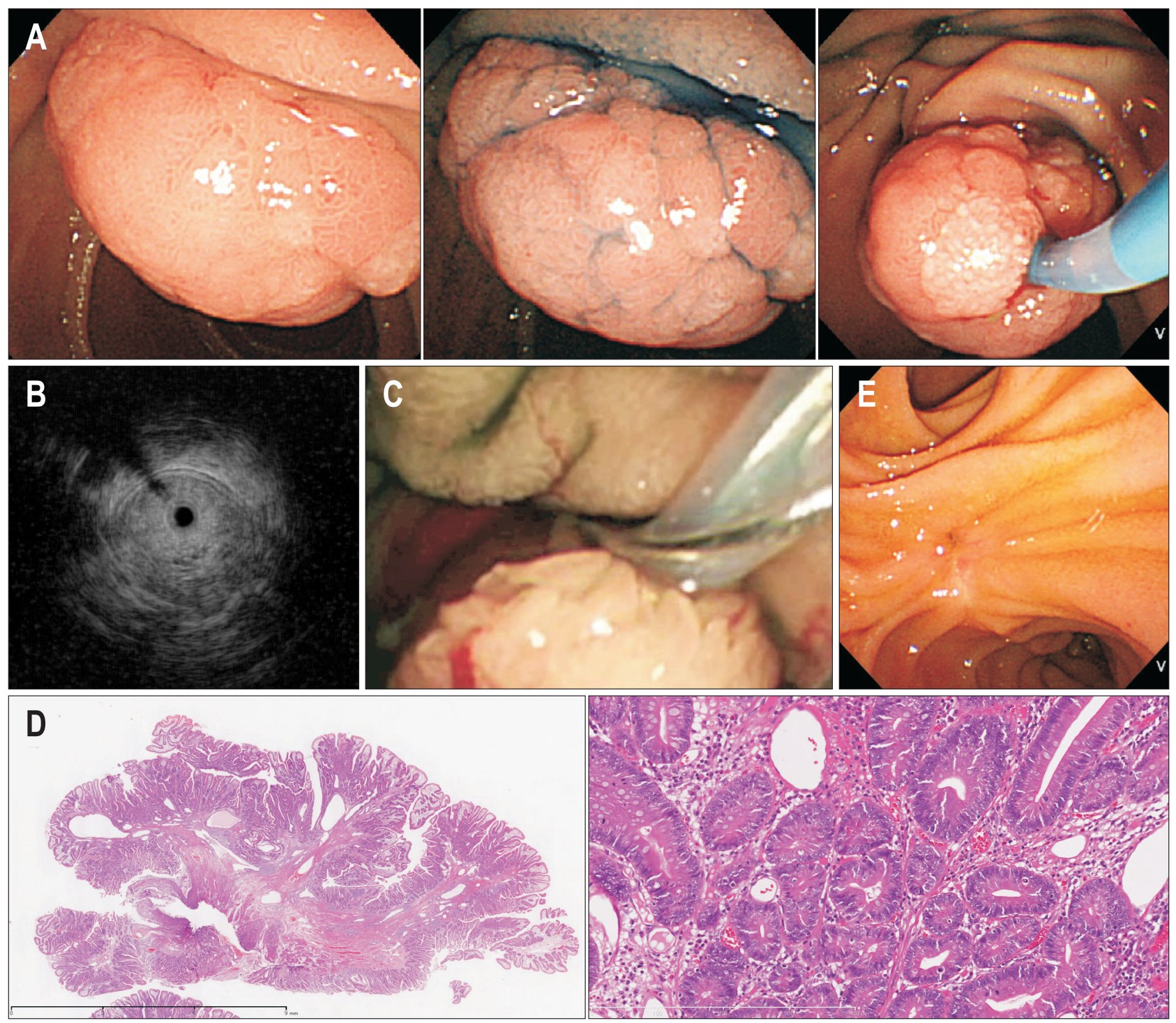

Fig. 1. Presentation of ampullary tumor and endoscopic resection procedures (A, C, E) and histological findings of a resected tumor specimen (B). (A) Endoscopic findings of the ampullary tumor. A 2-cm exposed reddish tumor was identified in the papilla of Vater. (B) Endoscopic ultrasonography revealed that the ampullary tumor had not invaded the duodenum, pancreas, terminal common bile duct, or main pancreatic duct. (C) Endoscopic doublesnare papillectomy was performed. After grasping and pulling the tumor with the pulling snare, the tumor was safely and easily grasped by the cutting snare. (D) Histological examination demonstrated tubular adenoma with moderate to severe dysplasia. No lymphatic invasion or vascular involvement was identified ( $\times 200)$. (E) Endoscopy of the ampullary portion of the duodenum following endoscopic papillectomy revealed no neoplastic lesions.

pancreatic duct, and a nasobiliary drainage tube was placed in the bile duct. There were no adverse events. Neither macro- nor microscopic tumor recurrence was observed. The resected specimen consisted of a whitish exophytic tumor, 20×9.6 mm in size, in the ampulla of Vater. Histological examination verified tubular adenoma with moderate to severe dysplasia (Fig. 1D). Follow-up endoscopy with biopsy was performed at 3 and 6 months postoperatively and every 6 months thereafter. However, no recurrence was observed after 48 months of follow-up (Fig. 1E).

\section{DISCUSSION}

Double-snare retracting en bloc papillectomy is an effective and feasible treatment for patients with lesions of the major duodenal papilla. This method is also important clinically, as it can provide an accurate diagnosis, ensure an appropriate resection margin, and reduce the risk of unnecessary surgery. Previous reports of EP procedures have described completion rates of $77 \%$ to $84 \% .^{10,12,13}$ In this study, we achieved a $100 \%$ success rate for en bloc resection using the double-snare retracting papillectomy technique. Although this study included only a small number of patients, the results are certainly encouraging, and further data will be accumulated in the future.

En bloc resection is considered fundamental for the treatment of neoplastic lesions and permits precise histopathological evaluation of the resected specimen. Desilets et al. ${ }^{2}$ recommended 
piecemeal snare resection to successfully treat adenomas of the major duodenal papilla without a risk of recurrence and with a reduction in the frequency of adverse events, such as perforation and bleeding. However, piecemeal resection can increase the risk of tumor seeding, increase the number of ERCP sessions that are required for eradication, and prevent precise histopathological assessments of the resection specimens. Indeed, in the series by Desilets et al., ${ }^{2}$ an average of 2.7 ERCP procedures were needed for piecemeal resection. In contrast, en bloc resection requires only a single treatment session.

It is commonly agreed that the indication for EP is nonmalignant adenoma of the papilla of Vater, but establishing a diagnosis of adenoma in the area of the papilla of Vater is difficult. A preresection diagnosis must therefore be carefully established; in particular, ampullary cancer must be ruled out. EUS and IDUS are extremely useful for such assessments because these modalities can demonstrate spread of the tumor within the bile and/or pancreatic ducts, as well as extension beyond the muscle layer of the duodenum. Our results suggest that all 12 of the cases were localized within the ampullary region without intraductal invasion or muscle layer involvement. The evaluation of the surgical margins in the resected tissues revealed the complete resection of eight tumors and barely negative or unclear surgical margins in four tumors. As a result, the EP recurrence rate in the 12 patients was fairly high at 25\% (3/12), although we succeeded in eradicating the residual lesions. We could not identify the reason for the relatively high recurrence rate, due to the study's small sample size, and further research is needed. Adverse events after EP treatment included pancreatitis, bleeding perforation, cholangitis, and papillary stenosis, reportedly occurring at rates of $15 \%$ to $22 \% .^{6,8,10,12,13}$ In the present study, one case of pancreatitis and one case of hemorrhage occurred (8.3\%, 1/12). Although these patients recovered with endoscopic and/ or medical treatments, the percentage of severe adverse events is not negligible. A recent prospective randomized controlled trial evaluating the role of pancreatic stent placement showed a significant decrease in the occurrence of post-EP pancreatitis. ${ }^{14}$ In our study, pancreatic stent placement was accomplished in $91.7 \%$ of cases, a rather higher success rate than the $4 \%$ to $88 \%$ reported previously. ${ }^{1,6,15}$

In conclusion, we performed endoscopic double-snare retracting papillectomy for 12 ampullary tumors. In all cases, the papillary tumor was removed by en bloc resection. The use of the endoscopic double-snare technique may help to perform EP safely and completely. Further treatment experience is required before conducting a randomized study to compare the safety and efficacy of this technique with conventional EP.

\section{CONFLICTS OF INTEREST}

No potential conflict of interest relevant to this article was reported.

\section{REFERENCES}

1. Binmoeller KF, Boaventura S, Ramsperger K, Soehendra N. Endoscopic snare excision of benign adenomas of the papilla of Vater. Gastrointest Endosc 1993;39:127-131.

2. Desilets DJ, Dy RM, Ku PM, et al. Endoscopic management of tumors of the major duodenal papilla: refined techniques to improve outcome and avoid complications. Gastrointest Endosc 2001;54: 202-208.

3. Zadorova Z, Dvofak M, Hajer J. Endoscopic therapy of benign tumors of the papilla of Vater. Endoscopy 2001;33:345-347.

4. Norton ID, Gostout CJ, Baron TH, Geller A, Petersen BT, Wiersema MJ. Safety and outcome of endoscopic snare excision of the major duodenal papilla. Gastrointest Endosc 2002;56:239-243.

5. Aiura K, Imaeda H, Kitajima M, Kumai K. Balloon-catheter-assisted endoscopic snare papillectomy for benign tumors of the major duodenal papilla. Gastrointest Endosc 2003;57:743-747.

6. Catalano MF, Linder JD, Chak A, et al. Endoscopic management of adenoma of the major duodenal papilla. Gastrointest Endosc 2004;59:225-232.

7. Cheng CL, Sherman S, Fogel EL, et al. Endoscopic snare papillectomy for tumors of the duodenal papillae. Gastrointest Endosc 2004;60:757-764.

8. Bohnacker S, Seitz U, Nguyen D, et al. Endoscopic resection of benign tumors of the duodenal papilla without and with intraductal growth. Gastrointest Endosc 2005;62:551-560.

9. Bohnacker S, Soehendra N, Maguchi H, Chung JB, Howell DA. Endoscopic resection of benign tumors of the papilla of vater. Endoscopy 2006;38:521-525.

10. Boix J, Lorenzo-Zuniga V, Moreno de Vega V, Domenech E, Gassull MA. Endoscopic resection of ampullary tumors: 12-year review of 21 cases. Surg Endosc 2009;23:45-49.

11. Matsumoto T, lida M, Nakamura S, et al. Natural history of ampullary adenoma in familial adenomatous polyposis: reconfirmation of benign nature during extended surveillance. Am J Gastroenterol 2000;95:1557-1562.

12. Harano M, Ryozawa S, Iwano H, Taba K, Sen-Yo M, Sakaida I. Clinical impact of endoscopic papillectomy for benign-malignant borderline lesions of the major duodenal papilla. J Hepatobiliary Pancreat Sci 2011;18:190-194.

13. Itoi T, Tsuji S, Sofuni A, et al. A novel approach emphasizing preoperative margin enhancement of tumor of the major duodenal papilla with narrow-band imaging in comparison to indigo carmine chromoendoscopy (with videos). Gastrointest Endosc 2009; 69:136-141.

14. Cotton PB, Lehman G, Vennes J, et al. Endoscopic sphincterotomy complications and their management: an attempt at consensus. Gastrointest Endosc 1991;37:383-393.

15. Hernandez LV, Catalano MF. Endoscopic papillectomy. Curr Opin Gastroenterol 2008;24:617-622. 